\title{
Documentation of Competency on Sedation for Gastrointestinal Endoscopy
}

\author{
David J. Bjorkman \\ University of Utah School of Medicine, Salt Lake City, Utah, USA
}

\section{Key Words}

Competency $\cdot$ Training $\cdot$ Sedation

\begin{abstract}
There is general consensus in national and societal guidelines that training for sedation should be part of basic training for endoscopy. There is no clear consensus, however, on the structure of that training. More importantly, these same guidelines are often silent on the specific requirements to demonstrate competency for administration of sedation, ways to document that competency and measures to assure that competency is maintained. In the absence of data demonstrating improved outcomes with specific approaches, the process and principles in this paper are proposed as a starting point to be modified by future research and data.
\end{abstract}

Copyright $\odot 2010$ S. Karger AG, Basel

\section{Introduction}

Appropriate supervision and training is critical for developing skills necessary to perform any medical procedure. This concept is also true for conscious sedation, whether for endoscopy or other purposes. There is uniform agreement in the literature and all relevant societal guidelines agree that specific training is needed for both the endoscopic procedure and any sedation associated with that procedure [1-5]. Some even specify a specific number of supervised procedures required before competency can be assessed [5]. Unfortunately, these same guidelines are silent on how competency for sedation should be assessed and documented. Such documentation is implied, but not specified. The exception to this is the 2002 guideline from the American Society of Anesthesiologists, which outlined the principles of training necessary for the safe delivery of conscious sedation [1]. Since the publication of this guideline, there have been advances in sedation practice that have made explicit requirements for training more critical. Unfortunately, there are no data in the literature to guide us regarding the documentation of competency or its effect on patient outcomes. No study has demonstrated that the documentation of competency for sedation improves general outcomes in endoscopy. The scarcity of clinically significant adverse outcomes makes this a difficult endpoint to study. There are, on the other hand, far too many examples of bad outcomes that have occurred in the setting of untrained or undertrained providers of sedation. In the absence of appropriate trials providing data for firm recommendations, I propose the approach outlined below, subject to objective evaluation and improvement.

\section{KARGER}

Fax +41613061234

E-Mail karger@karger.ch

www.karger.com
(C) 2010 S. Karger AG, Basel

$0012-2823 / 10 / 0822-0121 \$ 26.00 / 0$

Accessible online at:

www.karger.com/dig
David J. Bjorkman, MD, MSPH

University of Utah School of Medicine

30 North 1900 East, Room 1C109 SOM

Salt Lake City, UT 84132 (USA)

Tel. +1 801581 6436, Fax +1 801585 3300, E-Mail david.bjorkman@hsc.utah.edu 


\section{Training in Sedation for Gastrointestinal Endoscopy}

All providers involved in sedation should have appropriate training and documentation of competency for their role in patient care. This includes physicians, nurses and other support personnel involved in the sedation, monitoring and potential rescue of a patient from a sedation-related event.

Competency for endoscopists should be achieved and documented as part of formal training in gastrointestinal endoscopy. This could be through a fellowship, residency or other formal training program. The competency of a specific provider should be documented prior to the initial granting of privileges for sedation. This documentation may include a training director's assessment, but should also include direct assessment by the hospital or organization granting privileges. There is no threshold number of supervised cases that implies competency. Individual assessment is required. Continued competency in sedation should not be assumed, but should be regularly reassessed and documented as part of the renewal of privileges for sedation and endoscopy. The competency of an individual provider should also be assessed when there is a significant complication of sedation, or when the endoscopy staff or other providers question the competency of the endoscopist.

\section{Documentation of Competency}

The documentation of competency can be done by various entities, depending upon the practice situation. These include the training program director, medical director of a free-standing endoscopy unit or group practice, a hospital credentialing body or, in some cases, through national or governmental organizations as part of individual or institutional certification or accreditation [example: ACLS (advanced cardiac life support) accreditation through the American Heart Association].

In a given institution, the training and documentation of competency should be uniform for all providers using sedation, regardless of the location (endoscopy unit, emergency department, etc.). A single institutional team consisting of experts in sedation, anesthesia and airway management should determine the appropriate training, requirements for competency and assessment for competency. The required training should conform to existing guidelines for content and include both didactic and handson training. Simulators can be used for both education and assessment. Direct observation of patient care is optimal.

\section{Monitoring of Competency}

After competency has been documented and privileges granted for sedation, the patient outcomes for each provider should be monitored. Data should be collected prospectively for all procedures and adverse events/interventions must be documented. Delayed adverse events should also be captured. Many endoscopy reporting systems facilitate the ongoing collection of provider-specific data on sedation and unanticipated interventions. These data should be regularly reviewed as part of the institutional or unit quality improvement efforts, benchmarking performance of each provider and the unit to comparable data locally, nationally and internationally.

Formal reassessment and documentation of competency should occur at regular intervals (usually simultaneously with renewal of hospital privileges). This reassessment should include a review of the clinical outcomes of the provider, completion of appropriate training and a formal reassessment of competency, similar to the periodic recertification required for ACLS. Some institutions may require continued ACLS certification as a condition of sedation privileges. Reassessment of competency need not wait for a specific time, but can be prompted by a sentinel event or any concern raised by colleagues.

\section{Conclusions}

A system of critical assessment and documentation of competency at the time that initial privileges for sedation are granted, coupled with an ongoing process to monitor patient outcomes and periodically reassess competency, is likely to assure continued quality of care and minimize adverse events; however, this should be prospectively studied.

Such a system would be much easier to establish if consensus could be reached on the appropriate training, assessment and documentation of competency. The current societal guidelines provide advice on the content of training, but do not give us the guidance needed for assessment and documentation of competency. Rather than publishing independent position statements, an international collaboration among specialties and a resulting consensus is needed to provide uniform expectations for competency that apply to all providers wherever sedation is used. 


\section{References}

Sedation for Gastrointestinal Endoscopy
1 American Society of Anesthesiologists: Practice guidelines for sedation and analgesia by non-anesthesiologists. Anesthesiology 2002;94:1004-1017.

-2 American Society of Gastrointestinal Endoscopy Standards of Practice Committee: Sedation and anesthesia in GI endoscopy. Gastrointest Endosc 2008;68:815-826.

3 Cohen LB, Delegge MH, Aisenberg J, et al: AGA Institute review of endoscopic sedation. Gastroenterology 2007;133:675-701.
4 American Society of Gastrointestinal Endoscopy Standards of Practice Committee: Training in patient monitoring and sedation and analgesia. Gastrointest Endosc 2007;66: 7-10.

5 American Society of Gastrointestinal Endoscopy Standards of Practice Committee: Methods of granting hospital privileges to perform gastrointestinal endoscopy. Gastrointest Endosc 2002;55:780-783. 